\title{
MRI evaluation of venous abnormalities in children with Sturge-Weber syndrome
}

\author{
Simone Mandelstam ${ }^{1}$, Savvas Andronikou ${ }^{2}$ \\ ${ }^{1}$ Department of Pediatric Radiology, Royal Children's Hospital, Flemington Road, \\ Parkville, Melbourne, Victoria, Australia \\ ${ }^{2}$ Department of Pediatric Radiology, Red Cross Children's Hospital, School of Child and \\ Adolescent Health, University of Cape Town, South Africa
}

\begin{abstract}
The fundamental abnormality in the SturgeWeber syndrome (SWS) is considered to be the lack of superficial cortical draining veins, which results in numerous collateral pathways of venous flow. Venous abnormalities have been described in detail using angiography but magnetic resonance imaging (MRI) has replaced angiography in the diagnosis of SWS. In this paper we aim to demonstrate the range and evolution of venous abnormalities in the SWS as seen on standard MRI sequences. Retrospective review of 16 MRI scans in a group of ten children with SWS was performed by two pediatric radiologists with emphasis on venous abnormalities. Eight patients had unilateral angiomas and five of these had ipsilateral choroid plexus hypertrophy. Two patients had bilateral angiomas both of which had bilateral choroid plexus hypertrophy. In two patients, the vein of galen was enlarged. Four children had abnormal venous structures including intramedullary veins and enlarged subependymal veins. There was evolution of the venous abnormalities in four of the five cases with follow-up imaging. Three patients had associated cerebral malformations. The predominant venous abnormalities in patients with SWS demonstrated by conventional
\end{abstract}

Correspondence: Savvas Andronikou, F.R.C.R., Department of Pediatric Radiology,

Red Cross Children's Hospital,

School of Child and Adolescent Health,

University of Cape Town, South Africa.

Tel: +27 (0)21658 5422, fax: +27 (0)21 6585101 .

E-mail: docsav@mweb.co.za

Received: August 14, 2003.

Revised: September 25, 2003.

Accepted: September 26, 2003.
MRI sequences included anomalous parenchymal veins. Deep venous enlargement as previously described on angiography, was an uncommon finding using MRI. Evolution of venous abnormalities was demonstrated in four of five patients who underwent follow-up examination. (J Pediatr Neurol 2004; 2(1): 29-32).

Key words: MRI, venous abnormality, venous occlusion, Sturge-Weber syndrome.

\section{Introduction}

The fundamental abnormality in the SturgeWeber syndrome (SWS) is considered to be the lack of superficial cortical draining veins. This results in numerous collateral pathways of venous flow manifesting as a leptomeningeal angioma with dilated transparenchymal, subependymal and deep veins. These abnormalities have been described in detail using angiography. However, angiography is invasive with associated morbidity and potentially severe complications and is no longer performed as part of the workup for SWS. Magnetic resonance imaging (MRI) is the imaging modality of choice for demonstrating the pial angioma but the detection of venous collaterals has only a limited description in the MRI literature. In this paper we aim to demonstrate the range and evolution of venous abnormalities in SWS as seen on MRI.

\section{Materials and Methods}

Retrospective review of 16 MRI scans in a group of ten children with SWS was undertaken by two pediatric radiologists. Standard MRI sequences were evaluated. These included multiplane, multislice T2, FLAIR and T1 pre and post contrast images. The venous structures evaluated included deep veins (internal cerebral veins, basal veins 


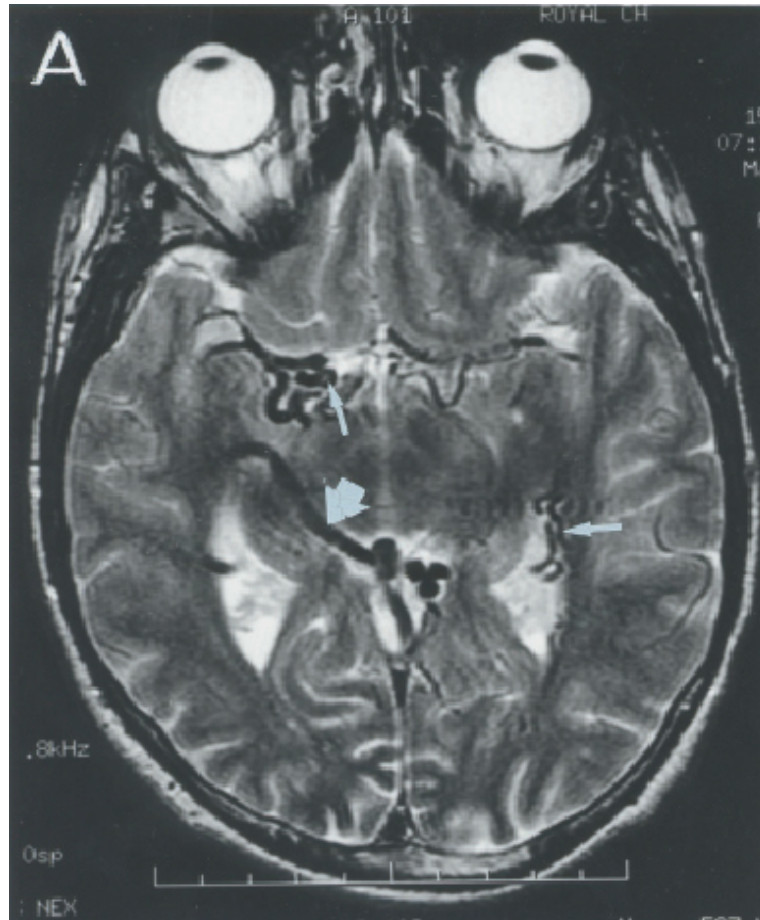

Figure 1a. Axial T2 weighted images of a patient with numerous venous abnormalities. Large right-sided deep medullary vein (large arrow) drains via the cisterna vell interpositi while other abnormal vessels are seen in the suprasellar cistern and within the trigone of the left lateral ventricle (small arrows).

of Rosenthal, vein of Galen, straight sinus), subependymal veins and transparenchymal medullary veins. Ten patients with SWS were investigated using MRI. Five patients underwent a single MRI, four had two scans and a single patient had 3 scans. In total, 16 scans were performed in ten patients. There were seven boys and three girls. The ages ranged from 3 days to 17 years at initial examination. Seven of the initial scans were performed when the patients were below 3 years of age. Four patients had scans below 6 months of age with the youngest being only 3 days of age. Three of these patients had follow-up scans, one at 9 months, one at 15 months and one at 5 years, respectively. Three patients had initial scans performed between the ages of 13 years and 18 years. Of these, one patient had two follow-up scans.

\section{Results}

A total of ten patients were included. Two patients had bilateral pial angiomas demonstrated on MRI. In one of these cases, an initial MRI performed at 4 months of age demonstrated a left sided angioma only, and a repeat study at 15 months demonstrated bilateral angiomas (left larger than right). Of the remaining eight patients, four had angiomas on the right and four on the left.

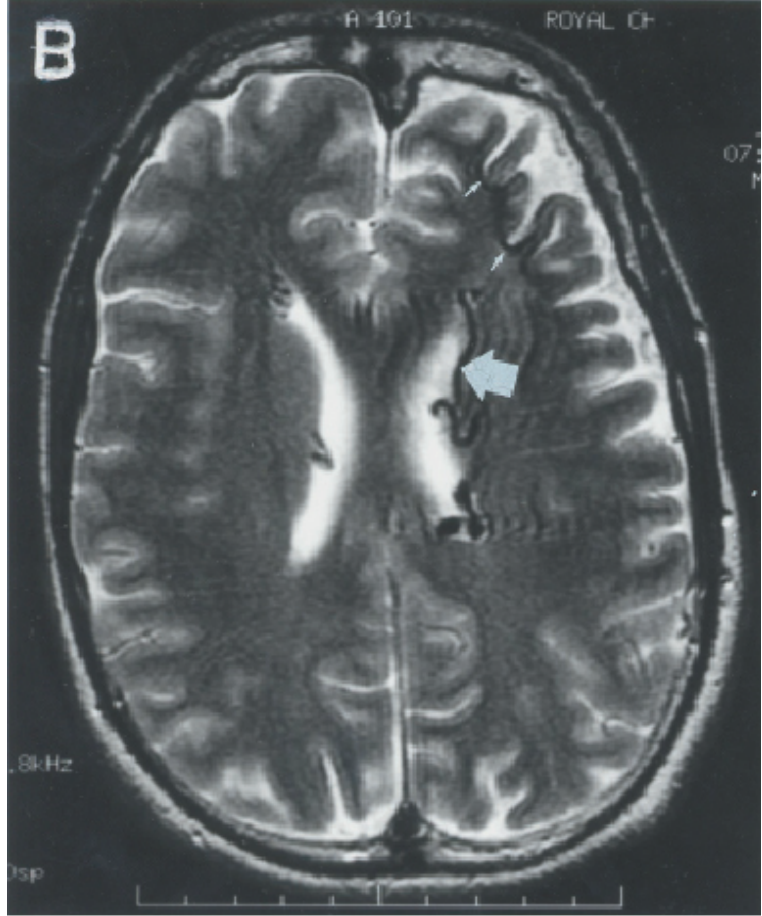

Figure 1b. Axial T2 weighted images of a patient with numerous venous abnormalities. Enlarged subependymal veins (large arrow) are demonstrated in the left lateral ventricle ipsilateral to the cerebral atrophy. Linear hypointensity representing cortical calcification is also present (small arrows).

Five patients demonstrated enlargement of the choroid plexus ipsilateral to the side of the angioma. One patient had a right-sided angioma with left sided choroid plexus hypertrophy. One of the cases with bilateral angiomas had bilateral choroid enlargement. The case, which initially demonstrated a left sided angioma, had ipsilateral choroid plexus hypertrophy on the first scan and bilateral hypertrophy on the follow-up scan which also demonstrated bilateral pial angiomas.

In two patients, the vein of Galen was enlarged. Abnormal subependymal or medullary veins were seen in a total of seven patients. In two of the cases, enlarged veins were demonstrated in the cisterna veli interpositi (Figures 1a and 1b).

Evolution of venous pathways was seen in four patients including the development of cerebellar medullary veins (Figure 2), anomalous veins draining into the vein of Galen and medullary veins involving the cerebral hemispheres.

Three out of the ten patients had associated cerebral malformations. One patient had a choroid fissure cyst and one had increased signal in the left thalamus. Two patients had cortical malformations on the ipsilateral to the side of the angioma. One of these patients also had ipsilateral mesial temporal sclerosis. The child with bilateral angiomas (larger on the left) had associated left cortical dysplasia. 


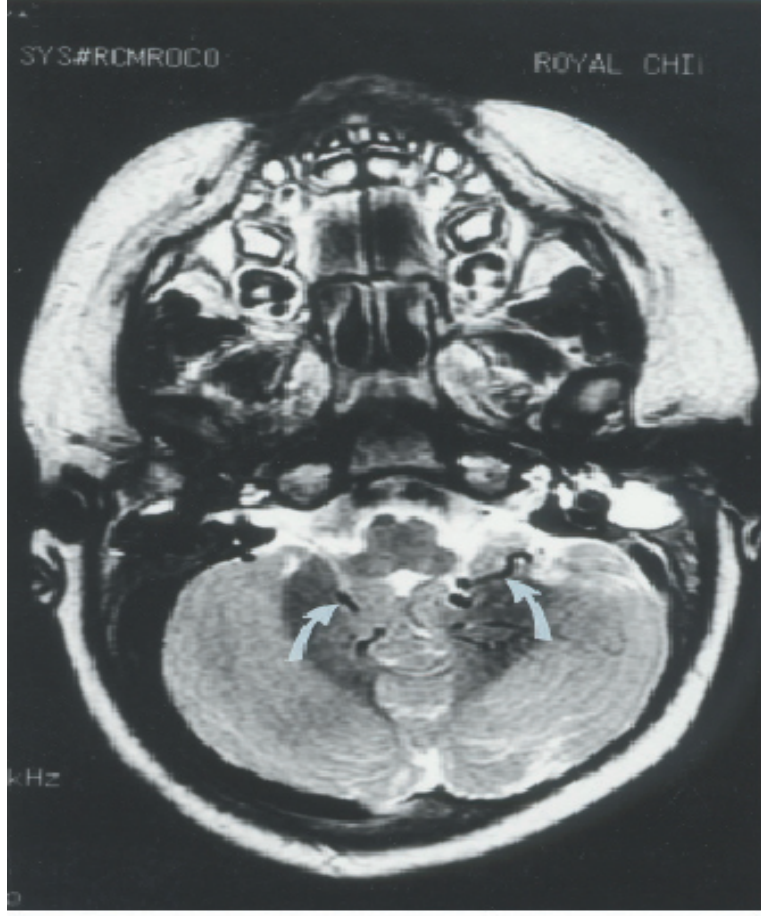

Figure 2. Axial T2 weighted image of the posterior fossa in a child with SWS. Anomalous medullary vessels are shown (arrows) draining radially towards the $4^{\text {th }}$ ventricle.

\section{Discussion}

SWS is a neurocutaneous syndrome characterized by leptomeningeal angiomatosis and an ipsilateral facial nevus known as a portwine stain. This is associated with a variety of central nervous system manifestations including seizures, mental retardation, dementia, hemiplegia, hemianopsia, buphthalmos and glaucoma (1-9).

The fundamental abnormality in SWS is aplasia or thrombosis of superficial cortical draining veins in the affected hemisphere/s (5-7,9-15). The result is redirection of blood with development of a leptomeningeal angioma and engorgement of the deep venous system via persistent embryological venous structures $(6,7,9-11,13,14,16)$. The collateral vessels usually have a transparenchymal, subependymal or periventricular location (1,13-15). The diversion of venous blood does not compensate fully and there is vascular stasis with chronic hypoxia resulting in tissue loss and dystrophic calcification $(5,10,11,15)$. These factors account for the characteristic radiological features of SWS including cerebral atrophy, gyral calcification and leptomeningeal enhancement (10).

Vascular abnormalities are not static over time and may relate to the age at which the patient is imaged $(11,13)$. Evolution is thought to occur due to thrombotic and non-thrombotic occlusion of veins $(9,11,16)$. Thickening and fibrosis of the medullary veins has been demonstrated at pathological examination and are thought to be the result of chronic venous hypertension $(9,11)$. These venous occlusions may modify the pattern of centripetal venous drainage (9). Five of our ten patients had follow-up scans and of these, four demonstrated changes in venous appearances over time. All four patients developed intramedullary or subependyal collaterals.

Catheter angiography no longer forms part of the routine assessment of a child with SWS (10). It is with the use of angiography, however, that the venous abnormalities in SWS have been demonstrated and reported in detail $(5,6,11,13,14,17,18)$. Benedikt et al. (13) reported the presence of enlarged deep veins in nine of 11 children with SWS on angiography. The internal cerebral veins were most prominently involved but there were also enlarged basal veins of Rosenthal, medullary veins and subependymal veins (13). The venous abnormalies in SWS have been described on cross-sectional imaging $(4,6,10)$, as has the increased prevalence of dural arteriovenous fistulae, cavernous angiomas and developmental venous anomalies (10). The disturbed venous circulation reportedly manifests on MRI as congested cerebral veins, best appreciated on T2 weighted sequences as prominent signal voids (3-5,7). Our literature search yielded 12 papers describing the venous pattern on MRI in children with SWS (1-8,11-14). Ten of these papers describe a total of 70 patients with venous abnormality in 28 of these patients $(40 \%)$. The reported findings include decreased cortical veins, prominent subependymal, periventricular, medullary and internal cerebral veins (1-4,7,8,11-14). Most of these reports do not indicate the relative incidence of each of the venous abnormalities and more often than not the abnormality is simply described as enlargement of the deep venous system. In our study, there was poor correlation with reported angiographic findings of enlarged internal cerebral veins and basal veins of Rosenthal. None of our patients showed dilated internal cerebral veins. Only one case with a unilateral angioma demonstrated enlargement of the ipsilateral basal vein of Rosenthal. We also evaluated the vein of Galen, which was enlarged in two cases. The straight sinus was not enlarged in any of our cases. Other reported venous abnormalities include decreased or absent superficial cortical veins, abnormal veins with 'bizarre' courses, non-filling of the superior sagittal sinus from an ipsilateral injection and occlusions of the superior sagittal sinus and deep veins by thrombus $(5,6,11,13,14,17,18)$. Abnormal subependymal or medullary veins were seen in a total of seven patients in our study. In two of the cases, enlarged veins were demonstrated in the cisterna veli interpositi (Figures 1a and 1b). We found that the vessels were best evaluated with a combination of assessing T2 vascular flow voids and 
T1 post contrast images. (All the children with SWS routinely receive Gadolinium as part of the study protocol).

The major limitation of our study is the difficulty assessing what constitutes a "normal" venous caliber in children of different ages, as there are no standardized measurements for comparison. In the cases with unilateral angiomas, one may use the non-affected side as the control side. However, this does not take into account the normal variation in size of venous structures, bilateral disease, or the development of contralateral venous pathways.

\section{Conclusion}

Evaluation of venous structures on standard brain MRI sequences demonstrated abnormalities in $70 \%$ of children with SWS. Unlike previous angiographic studies, which commonly demonstrated dilated deep venous structures, only one of our cases had this feature. The commonest abnormality was the presence of anomalous medullary and subependymal vessels. Evolution of venous abnormalities over time was demonstrated in four of five patients who had follow-up imaging. The identification of abnormal venous pathways on standard MRI sequences can be used to make an early diagnosis in children and may be useful in detecting bilateral disease. Radiologists should also be aware that evolution of abnormalities, may occur over a period of time, and include the appearance of abnormal venous structures. Cortical dysplasias and other abnormalities are notable associated findings, which may result in seizures.

\section{References}

1. Marti-Bonmati L, Menor F, Mulas F. The SturgeWeber syndrome: correlation between the clinical status and radiological CT and MRI findings. Child's Nerv Syst 1993; 9: 107-109.

2. Marti-Bonmati L, Menor F, Poyatos C, Cortina H. Diagnosis of Sturge-Weber syndrome: comparison of the efficacy of CT and MR imaging in 14 cases. AJR Am J Roentgenol 1992; 158: 867-871.

3. Elster AD, Chen MY. MR imaging of Sturge-Weber syndrome: role of gadopentetate dimeglumine and gradient-echo techniques. AJNR Am J Neuroradiol 1990; 11: 685-689.

4. Vogl TJ, Stemmler J, Bergman C, Pfluger T, Egger E, Lissner J. MR and MR angiography of Sturge-Weber syndrome. AJNR Am J Neuroradiol 1993; 14: 417425.

5. Sperner J, Schmauser I, Bittner R, et al. MR-imaging findings in children with Sturge-Weber syndrome. Neuropediatrics 1990; 21: 146-152.

6. Hamano K, Ito M, Inai K, Nose T, Takita H. A case of Sturge-Weber syndrome with peculiar venous abnormalities. Child's Nerv Syst 1993; 9: 491-493.

7. Chamberlain MC, Press GA, Hesselink JR. MR imaging and $\mathrm{CT}$ in three cases of Sturge-Weber syndrome: prospective comparison. AJNR Am J Neuroradiol 1989; 10: 491-496.

8. Reid DE, Maria BL, Drane WE, Quisling RG, Hoang KB. Central nervous system perfusion metabolism abnormalities in Sturge-Weber syndrome. J Child Neurol 1997; 12: 218-222.

9. Cure JK, Holden KR, Van Tassel P. Progressive venous occlusion in a neonate with Sturge-Weber syndrome: demonstration with MR venography. AJNR Am J Neuroradiol 1995; 16: 1539-1542.

10. Griffiths PD. Sturge-Weber syndrome revisited: the role of neuroradiology. Neuropediatrics 1996; 27: 284-294.

11. Coley SC, Britton J, Clarke A. Status epelepticus and venous infarction in Sturge-Weber syndrome. Child's Nerv Syst 1998; 14: 693-696.

12. Wasenko JJ, Rosenbloom SA, Duchesneau PM, Lanzieri CF, Weinstein MA. The Sturge-Weber syndrome: comparison of MR and CT characteristics. AJNR Am J Neuroradiol 1990; 11: 131-134.

13. Benedikt RA, Brown DC, Walker R, Ghaed VN, Mitchell M, Gayer CA. Sturge-Weber syndrome: cranial MR imaging with Gd-DTPA. AJNR Am J Neuroradiol 1993; 14: 409-415.

14. Pascual-Costroviejo I, Diaz-Gonzalez C, GarciaMelian RM, Gonzalez-Casado I, Munoz-Hiraldo E. Sturge-Weber syndrome: study of 40 patients. Pediatr Neurol 1993; 9: 283-288.

15. Hosokawa $\mathrm{C}$, Inoue $\mathrm{Y}$, Yoshimura $\mathrm{H}$, et al. Transient increase in cerebral blood flow in a patient with Sturge-Weber syndrome. J Comput Assist Tomogr 1998; 22: 980-983.

16. Portilla P, Husson B, Lasjaunias P, Landrieu P. Sturge-Weber disease with repercussion on the prenatal development of the cerebral hemisphere. AJNR Am J Neuroradiol 2002; 23: 490-492.

17. Terdjman P, Aicardi J, Sainte-Rose C, Brunelle F. Neuroradiological findings in Sturge-weber syndrome and isolated pial angiomatosis. Neuropediatrics 1991; 22: 115-120.

18. Fishman MA, Baram TZ. Megalencephaly due to impaired cerebral venous return in a Sturge-Weber variant syndrome. J Child Neurol 1986; 1: 115-118. 